\title{
Medical physics workforce modelling: do we need what we want?
}

\author{
Claire Dempsey ${ }^{1,2,3,4}$
}

Published online: 1 July 2018

(c) Australasian College of Physical Scientists and Engineers in Medicine 2018

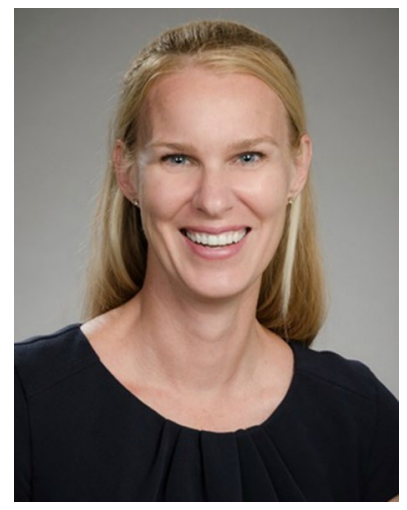

"Please Sir, I want some more."

While Oliver Twist [1] was talking about a basic necessity of life with this request, many medical physicists are left crying these words when they start thinking about medical physics staffing numbers in departments across Australasia. As part of ACPSEM departmental accreditation for TEAP purposes, the F2000 model [2] has been the benchmark for suitable staffing levels. But is this model appropriate for departments in 2018 (and into the future) and how have Australasian departments changed over the past decade, particularly in light of TEAP graduates entering the profession, with TEAP now 15 years old? How do we, as a profession, decide what staffing numbers a department truly "needs" against the numbers we "want" to have?

In recent years, several groups have tried to measure and define workload versus equipment versus staffing models for radiation therapy services [3-6], yet there seems to be

\section{Claire Dempsey}

claire.dempsey@calvarymater.org.au

1 Calvary Mater Newcastle Hospital, Waratah, NSW, Australia

2 University of Newcastle, Callaghan, NSW, Australia

3 University of Washington, Seattle, WA, USA

4 Australasian College of Physical Scientists and Engineers in Medicine, Mascot, NSW, Australia no universal consensus on what this ratio should be. This is difficult given the different roles and definitions of a medical physicist in an individual department as well as whether 'technicians' or 'physics assistants' are employed. Unfortunately, health economics makes things even more complicated and the increasing prevalence of private practise radiation therapy departments globally can skew survey numbers against us.

A thorough analysis of Australasian medical physicists' versus equipment versus technique versus patient numbers versus operating hours versus radiation incidents (both major and minor) is well beyond the scope of this editorial but would certainly make for interesting reading and perhaps great ammunition for those seeking to improve their staffing budget. In my role as ACPSEM ROMP training coordinator, I have been heavily involved in departmental accreditation since 2014 and have seen the good, the bad and the scary. Initial analysis of data from ACPSEM departmental accreditation records spanning 2014-2018 shows that all departments are below F2000 levels, some I would call dangerously so, and that there are clear differences between public, private, metropolitan and remote facilities.

Previous medical physics workforce surveys have been conducted in 2006, 2009 and 2012 by Howell Round [7-9]. These surveys were very comprehensive, covering not only radiation oncology but also diagnostic imaging and nuclear medicine. Ideally, it would be fantastic to be able to continue gathering this important workforce data and I would gladly help anyone who wishes to volunteer for this massive task. In 2006, there was a shortfall of qualified physicists of 32\% in Australia and 15\% in New Zealand based on the simplified F2000 ratio of 1.7 qualified physicists per linac [7]. In 2009 this shortfall grew to 35\% in Australia and 23\% in New Zealand [8]. In 2012, the shortfall in Australia grew further to $37 \%$ but fell in New Zealand to $13 \%$ [9]. In Australia, between 2006 and 2012 there appeared to be more additional linacs installed (67) than additional qualified medical physicists employed (64). Using a sample dataset of ACPSEM accredited departments, it appears that these shortfalls have been improving. Based purely on linac 
numbers and a ratio of 1.7 qualified physicists per linac, Australia now has a shortfall of only $10 \%$ and New Zealand is actually in the black with a $12 \%$ oversupply of qualified physicists (although I strongly suspect my New Zealand colleagues would laugh at the idea of their department being "overstaffed")! I can only speculate that these improvements are a flow on effect as a result of more and more graduates coming out of TEAP. Delving deeper into the data and looking more specifically at a departmental level it would seem that large data 'averaging' may not be entirely appropriate as a workforce summary tool because the spread of qualified medical physicists throughout Australasian departments is certainly not uniform.

In 2009, the Department of Health and Aging in Australia commissioned a report to review the current status and capacity of the radiation oncology workforce (including medical physics) [10]. Based on data collected in 2008 there was an average of 1.6 and 1.0 qualified physicists per linac in the public and private sectors respectively. This data contradicts the study by Howell in 2009 [8] which indicated there were 27 fewer qualified ROMPs in Australia, making the ratios much lower. That aside, there is some good news for those in the public sector, with my current data indicating that there is now an average of 2.0 physicists per linac but with a very large range of 0.6-3.0. Unfortunately in the private sector, this ratio has remained steady at 1.0 physicists per linac (range 0.7-2.3).

For each departmental accreditation, the ACPSEM requires a completed F2000 spreadsheet which allows for a department-specific assessment of staffing and workload. This includes items like brachytherapy and superficial/orthovoltage therapy and incorporates workload due to IMRT (but not VMAT or SBRT) and EPID (but not CBCT), patient treatment numbers, radiation safety as well as education and teaching (not including TEAP). According to data provided by each individual department, the ROMP to linac ratio should now be closer to 3.0 rather than 1.7. This is consistent across both public (3.1) and private (2.4) departments. Using a value of 3.0 qualified physicists per linac, the current shortfall of physicists grows to a staggering $49 \%$ in Australia and 36\% in New Zealand.

I have no doubt that all medical physicists in Australasia believe they work hard and beyond the scope for which they are paid (the pay-debate, whilst extremely valid, is not covered in this editorial). Data suggests that some are working extra-hard (up to three times harder) at just maintaining a safe, clinical environment with innovation, research and advanced practice improbable, if not impossible. Is this the best use of our skills? Does this create burn-out and fatiguerelated costs to a department? Or worse still, is this a ticking time bomb which could result in unimaginable dangers to patients, staff and the public?
Looking at the figures that Australasian departments have coped with for the past decade, and the improvements in technique and technology across that time, to an outsider it would seem that we are doing just fine with the numbers we have. I am sure those who pull the purse-strings are thinking "Hey, it seems to be working now, so why spend money on extra staff?". Obviously, recruitment is limited to the number of staff that the government or private provider is willing to fund and clearly there is a need to somehow define a realistic standard for the medical physics workforce that those who control the finances will find palatable. The F2000 model tries to at least attempt to address many areas that fall within the realm of a medical physicist's responsibility, but given it was written almost two decades ago and that many (if not most) departments are currently working at numbers well below F2000 figures, a re-evaluation of this model is overdue. As part of any modelling, we must reflect on where we have come from to ensure we set attainable goals for our future and whatever model we use must be convincing enough to those who will ultimately decide our workforce fate and yet still provide increased benefits to those who need it most, our patients.

\section{References}

1. Oliver Twist (1839) Charles Dickens

2. Oliver L, Fitchew R, Drew J (2001) Requirements for radiation oncology physics in Australia and New Zealand. Aust Phys Eng Sci Med 24(1):1

3. Battista JJ, Clark BG, Patterson MS et al (2012) Medical physics staffing for radiation oncology: a decade of experience in Ontario, Canada. J Appl Clin Med Phys 13(1):93-110

4. Dunscombe P, Grau C, Defourny N et al (2014) Guidelines for equipment and staffing of radiotherapy facilities in the European countries: Final results of the ESTRO-HERO survey. Radiother Oncol 112:165-177

5. Institute of Physics and Engineering in Medicine (IPEM) (2017) Policy Statement: Recommendations for the provision of a physics service to radiotherapy

6. Round WH, Tay YK, Ng KH et al (2010) AFOMP Policy Statement No 2: recommended clinical radiation oncology medical physicist staffing levels in AFOMP countries. Aust Phys Eng Sci Med 33(1):7-10

7. Round WH (2007) A survey of the Australasian clinical medical physics and biomedical engineering workforce. Aust Phys Eng Sci Med 30(1):13

8. Round WH (2010) A 2009 survey of the Australasian clinical medical physics and biomedical engineering workforce. Aust Phys Eng Sci Med 33(1):153-162

9. Round WH (2013) A 2012 survey of the Australasian clinical medical physics and biomedical engineering workforce. Aust Phys Eng Sci Med 36(1):147-157

10. HeathConsult Pty Ltd. for Australian Department of Health and Ageing (2009) Radiation oncology workforce planning final report 